\title{
AVALIAÇÃO DA TÉCNICA DE LISE MEDIADA POR COMPLEMENTO EM PACIENTES CHAGASICOS CRÓNICOS TRATADOS COM DROGAS TRIPANOSOMICIDAS
}

\author{
Antonio Marcos de Aparecida LeVy (1), Vera Lucia PEREIRA (1) \& Elias BoAINAIN (2)
}

\section{R E S U M O}

Os níveis de anticorpos líticos foram determinados em pacientes chagásicos crônicos, tratados com niffurtimox ou benzonidazol, através da Lise Mediada por Complemento (LMCo). Dois grupos de pacientes foram estudados: um grupo tratado há mais de seis anos e outro há menos de seis anos. Ambos os grupos, após o tratamento, apresentaram xenodiagnósticos negativos, embora as provas sorológicas permanecessem reagentes. Foram incluídos um grupo controle negativo com provas sorológicas não reagentes e um grupo controle positivo com provas sorológicas e parasitológicas positivas. Para a LMCo foram utilizadas duas amostras de cada paciente, obtidas em ocasiōes diferentes, tanto dos grupos estudados quanto do grupo controle positivo. Em vista dos resultados foi calculada a sensibilidade da reação $(83.3 \%)$ e a especificidade $(100,0 \%)$. Nos grupos estudados observou-se que cerca da metade dos pacientes apresentaram lise menor do que $20 \%$, podendo, este resultado, corroborar a "cura parasitológica". Notou-se que $43,6 \%$ dos pacientes tratados há mais de seis anos apresentaram resultados contraditórios, ora negativos, ora positivos, dependendo da amostra. Tais resultados foram considerados inconclusivos, em virtude das provas parasitológicas permanecerem negativas. Um seguimento a longo prazo poderá esclarecer o significado desses resultados.

UNITERMOS: Técnica de lise mediada por complemento; Doença de Chagastratamento.

\section{N T R O D U C}

Entre as dificuldades encontradas pelo clínico na avaliação da terapêutica durante a fase crônica da doença de Chagas ressalta a demonstração da presença do Trypanosoma cruzi antes do tratamento e uma prova decisiva que evidencie o seu desaparecimento após a medicação. Entre os métodos preconizados para o diagnós tico parasitológico do T. cruzi destacam-se o xenodiagnóstico e a hemocultura. O primeiro, embora trabalhoso, tem-se mostrado a técnica de eleição, com sensibilidade em torno de $40 \%^{2}$. A hemocultura apresenta resultados variados conforme o pesquisador ${ }^{5,8}$, porém com sensibilidade nāo superior à do xenodiagnóstico.

O aparecimento de trabalhos sobre anticorpos líticos revelou a possibilidade de uma nova técnica para a avaliaçāo da eficácia terapêutica, pois tais anticorpos só apareceriam na infecçāo ativa pelo $\mathbf{T}$. cruzi, estando ausentes com o desaparecimento da infecção ${ }^{3,9,11}$.

Trabalho realizado no setor de Miocardiopatias do Instituto "Dante Pazzanese" de Cardiologia, Sāo Paulo, SP, Brasil, financiado parcialmente pelo "UNDP/World Bank/WHO Special Programme for Research and Training in Tropical Diseases", Grant 850406. 
LEVY, A. M. de A.; PEREIRA, V. L. \& BOAINAIN, E. - Avaliação da técnica de lise mediada por complemento em pacientes chagásicos crônicos tratados com drogas tripanosomicidas. Rev. Inst. Med. trop. São Paulo, 30 (1): 32.39 .1988

Os niveis de anticorpos líticos através da lise mediada por complemento foram pesquisados em pacientes chagásicos crônicos, no Instituto "Dante Pazzanese" de Cardiologia.

O objetivo do presente estudo foi avaliar esta técnica como critério de "cura parasitológica" em pacientes chagásicos submetidos à quimioterapia.

\section{MATERIAL E MÉTODOS}

1 - Soros

1-1 - Grupo I

Soros de 20 pacientes cardiopatas não chagásicos, com provas sorológicas convencionais para doença de Chagas, não reagentes.

\section{1-2 - Grupo II}

Soros de 18 pacientes chagásicos crônicos, com xenodiagnósticos e/ou hemoculturas positivos, ainda não submetidos à quimioterapia.

\section{1-3 - Grupo III}

Soros de 79 pacientes chagásicos crônicos tratados há mais de seis anos com nifurtimox ou benzonidazol e com xenodiagnósticos negativos após a terapêutica, mensalmente praticados.

\section{1-4 - Grupo IV}

Soros de 20 pacientes chagásicos crônicos tratados entre três e seis anos com benzonidazol, também com xenodiagnósticos negativos após a terapêutica e mensalmente praticados.

Os pacientes dos Grupos III e IV apresentaram provas sorológicas convencionais, para doença de Chagas, positivas antes e após a terapêutica. A técnica de lise mediada por complemento foi repetida pelo menos em duas ocasióes, em todos os pacientes, exceto nos pacientes do Grupo I.

\section{2 - Parasitas}

Camundongos isogênicos da linhagem A/Sn, com peso médio de $15 \mathrm{~g}$, foram imunossuprimi- dos com 200 a $350 \mathrm{mg} / \mathrm{kg}$ de ciclofosfamida, 48 a 72 horas após o inóculo ${ }^{14}$ de $\mathbf{T}$. cruzi, cepa $\mathrm{Y}^{15}$. O sangue, coletado no pico da parasitemia, foi submetido à centrifugação diferenciada para a separação dos tripomastigotas sangüíneos. Para o uso foram ajustados à concentraçāo de $4 \times 10^{6}$ a $6 \times 10^{6}$ parasitas $/ \mathrm{ml}$, para facilitar a contagem dos parasitas, visto que concentrações maiores tornam a leitura trabalhosa e sujeita a erros.

\section{3 - Técnica de lise mediada por complemento}

Foi utilizada a técnica descrita por KRETTLI ${ }^{10}$ com algumas modificaçōes: 1 - de acordo com UMEZAWA ${ }^{17} 100 \mu$ l de soro diluídos 1:2 e 1:4 foram adicionados a $50 \mu \mathrm{l}$ de parasitas; 2 - uso de placas de microtitulação em substituição aos tu bos de ensaio: 3 - a manutenção dos parasitas foi feita em meio Eagle com $5 \%$ ou $10 \%$ de soro de vitela.

Os soros do presente estudo foram congelados a $-20^{\circ} \mathrm{C}$ desde a sua extraçāo e inativaçāo por aquecimento a $56^{\circ} \mathrm{C}$ por 30 minutos, pouco antes do uso. Caso necessário, os soros foram repetidos apenas uma vez, evitando-se a manipulaçāo excessiva que favorecia a aglutinação de parasitas no controle com o "complemento inativo".

Foram considerados negativos os soros que apresentaram níveis de até $20 \%$ de lise dos tripomastigotas e como positivos os acima desse va$10 \mathrm{r}^{12}$. Os resultados foram expressos em porcentagem de lise.

\section{4 - Provas laboratoriais complementares}

\section{4-1 - Provas sorológicas convencionais}

Todos os soros utilizados para o estudo foram submetidos às seguintes provas: 1 - fixaçāo de complemento ${ }^{1} ; 2$ - imunofluorescência indireta ${ }^{4} ; 3$ - hemaglutinaçāo indireta com 2-mercaptoetanol $^{6} ;$ 4-aglutinação direta com 2-mercaptoetanol $^{16}$.

\section{4-2 - Provas parasitológicas}

O. xenodiagnóstico foi realizado com $40 \mathrm{nin}$ fas de Triatoma infestans com leituras após 30 e 60 dias, segundo a metodologia utilizada por 
LEVY, A. M de A.; PEREIRA, V. L. \& BOAINAIN, E. - Avaliaçào da técnica de lise mediada por complemento em pacientes chagásicos crönicos tratados com drogas tripanosomicidas. Rev. Inst. Med. trop. Sāo Paulo, 30 (1): 32-39, 1988

BOAINAIN ${ }^{2}$. Para a hemocultura, a papa de hemá cias foi semeada em meio LIT (liver infusion tryptose) e realizadas 4 leituras com intervalos respectivos de 15 dias $^{5}$.

\section{RESULTADOS}

As figuras $1,2,3$ e 4 traduzem os resultados de lise obtidos nos quatro grupos.

Os soros pertencentes ao Grupo I (Fig. 1) apresentaram lise de até $20 \%$, média de $10 \%$ na diluiçāo $1: 2$ (desvio padrāo $=7 \%$ ) e na diluiçāo $1: 4$ com média de $9 \%$ (desvio padrão $=7 \%$ ).

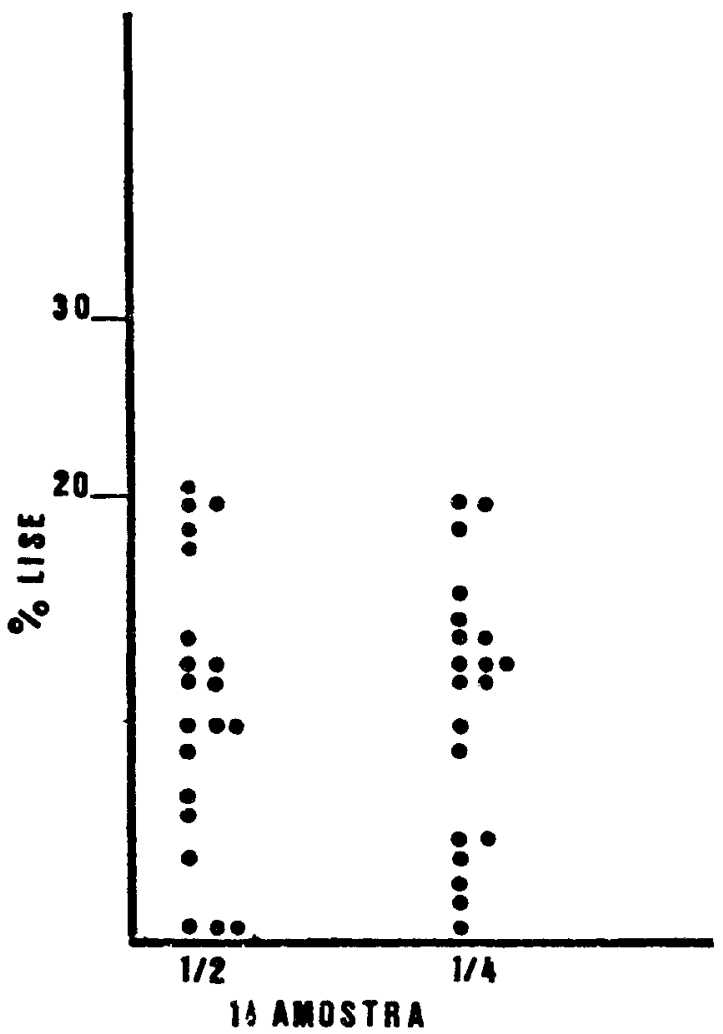

Fig. 1 - Grupo I: distribuiçâo dos resultados de lise nas dilui çōes $1: 2$ e $1: 4$ dos soros.

Os soros pertencentes ao Grupo II, pacientes nāo tratados com provas parasitológicas positivas (Fig. 2), apresentaram a seguinte distribuição: doze soros $(66.8 \%)$ mostraram taxas de lise maior que $20 \%$, três soros $(16.6 \%)$ mostraram taxas de lise abaixo de $20 \%$ e finalmente três soros $(16.6 \%)$ mostraram resultados variáveis, ora menores ora maiores que $20 \%$, tanto em uma ou ou tra amostra, quanto em uma ou outra diluiçào.

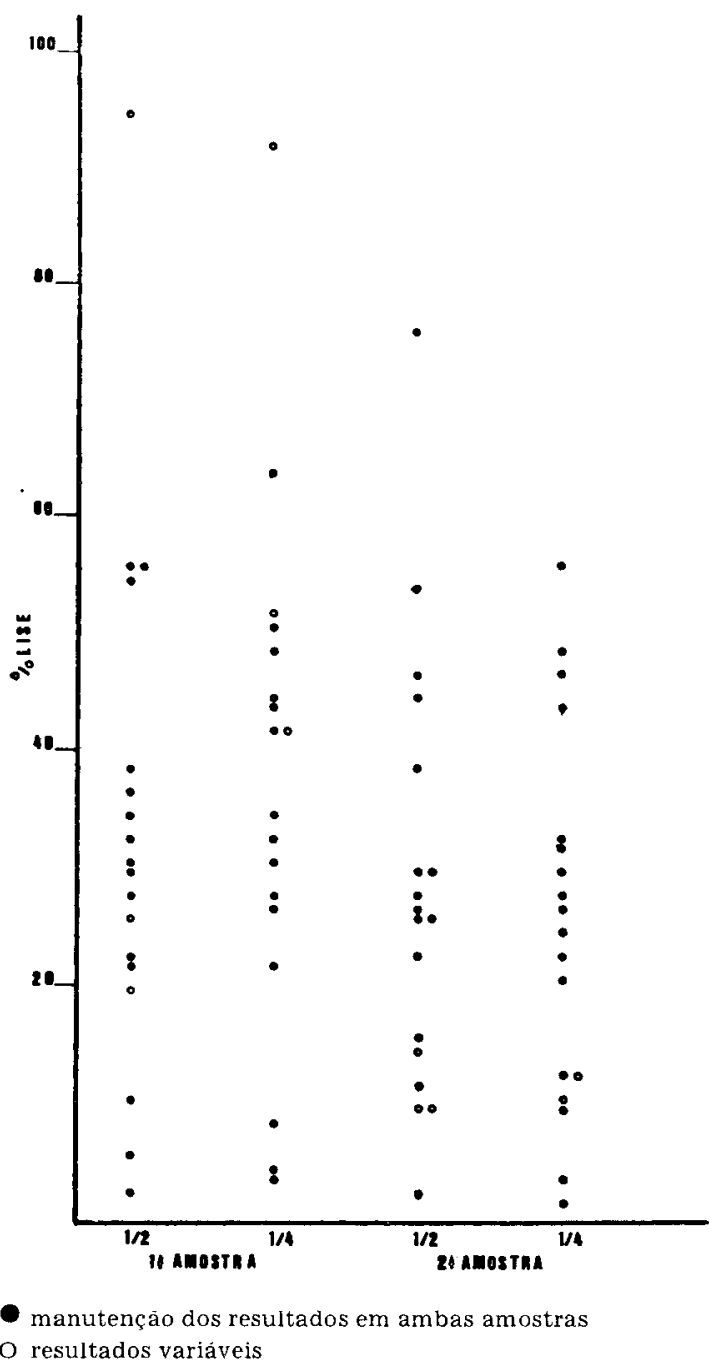

Fig. 2 - Grupo II: distribuiçāo dos resultados de lise nas duas amostras (diluiçóes $1: 2$ e $1: 4$ ) de soro.

A figura 3 mostra a distribuiçāo dos resultados obtidos nos soros dos pacientes do Grupo III, tratados há mais de seis anos. Trinta e seis soros $(45.6 \%)$ mostraram lise menor que $20 \%$, se te soros $(8,8 \%)$ apresentaram resultados acima de $20 \%$ e trinta e seis soros (45.6\%) mostraram resultados variáveis, ora menores, ora maiores que $20 \%$ em diferentes amostras ou diluiçōes. 
LEVY, A. M. de A.; PEReirA, V. L. \& BoAINAIN, E. - Avaliaçāo da técnica de líse mediada por complemento em pacientes chagásicos crónicos tratados com drogas tripanosomicidas. Rev. Inst. Med. trop. Sáo Paulo, 30 (1): 32-39, 1988.

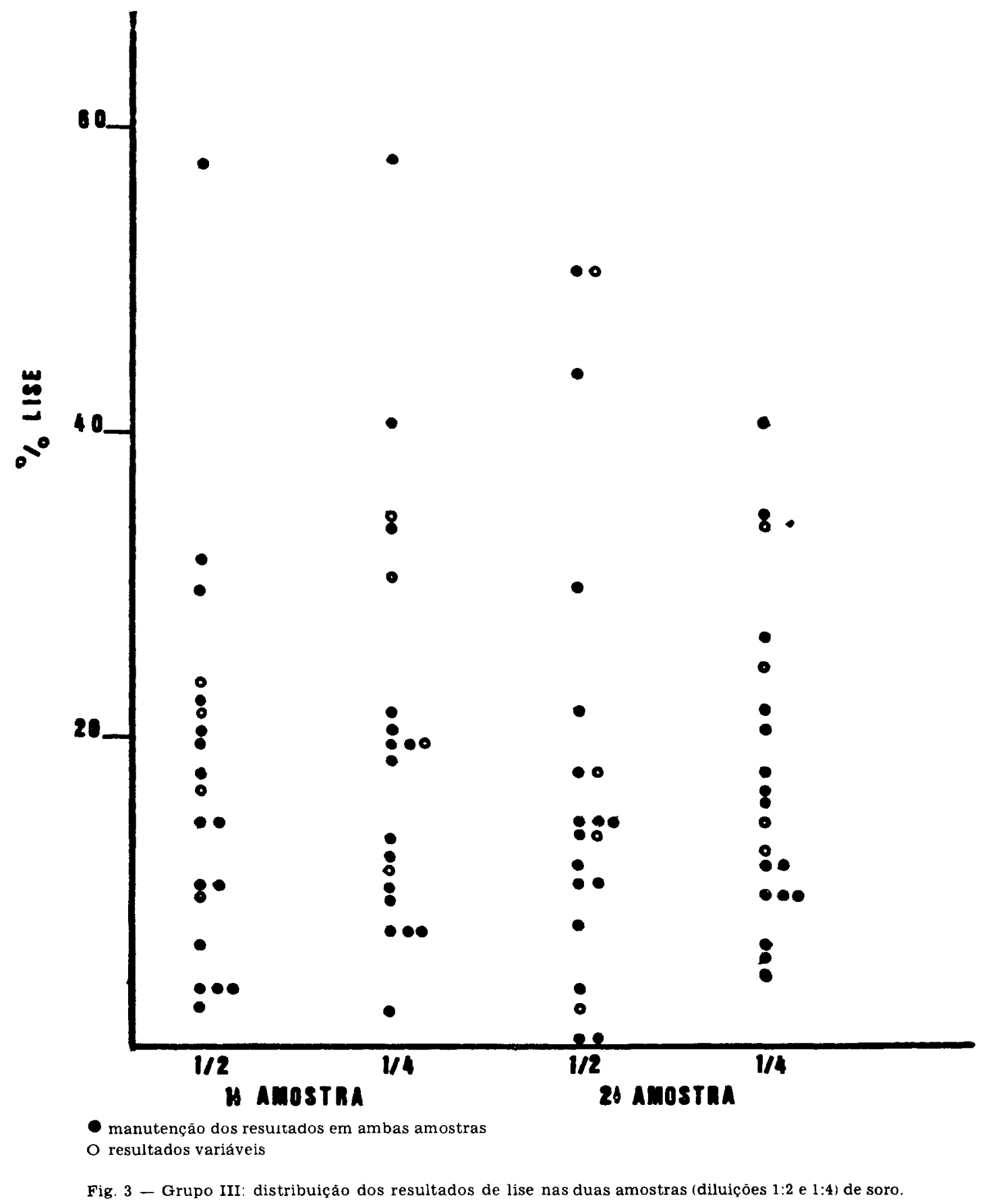

Nos soros do Grupo IV, pacientes tratados há menos de seis anos (Fig. 4). observou-se a mesma dispersão das amostras do Grupo III. Doze soros $(60.0 \%)$ mantiveram os resultados abaixo de $20 \%$ em ambas amostras, ao passo que quatro soros $(20.0 \%)$ mostraram valores acima de $20 \%$ (sendo que um deles com valores bastante elevados) e os quatro restantes $(20.0 \%)$ oscilaram nas duas amostras e/ou diluiçōes. 
LEVY. A. M. de A.: PEREIRA, V. L. \& BOAINAIN, E. - Avaliaçāo da técnica de lise mediada por complemento em pacientes chagásicos crónicos tratados com drogas tripanosomicidas. Rev. Inst. Med. trop. São Paulo, 30 (1): 3239.1988.

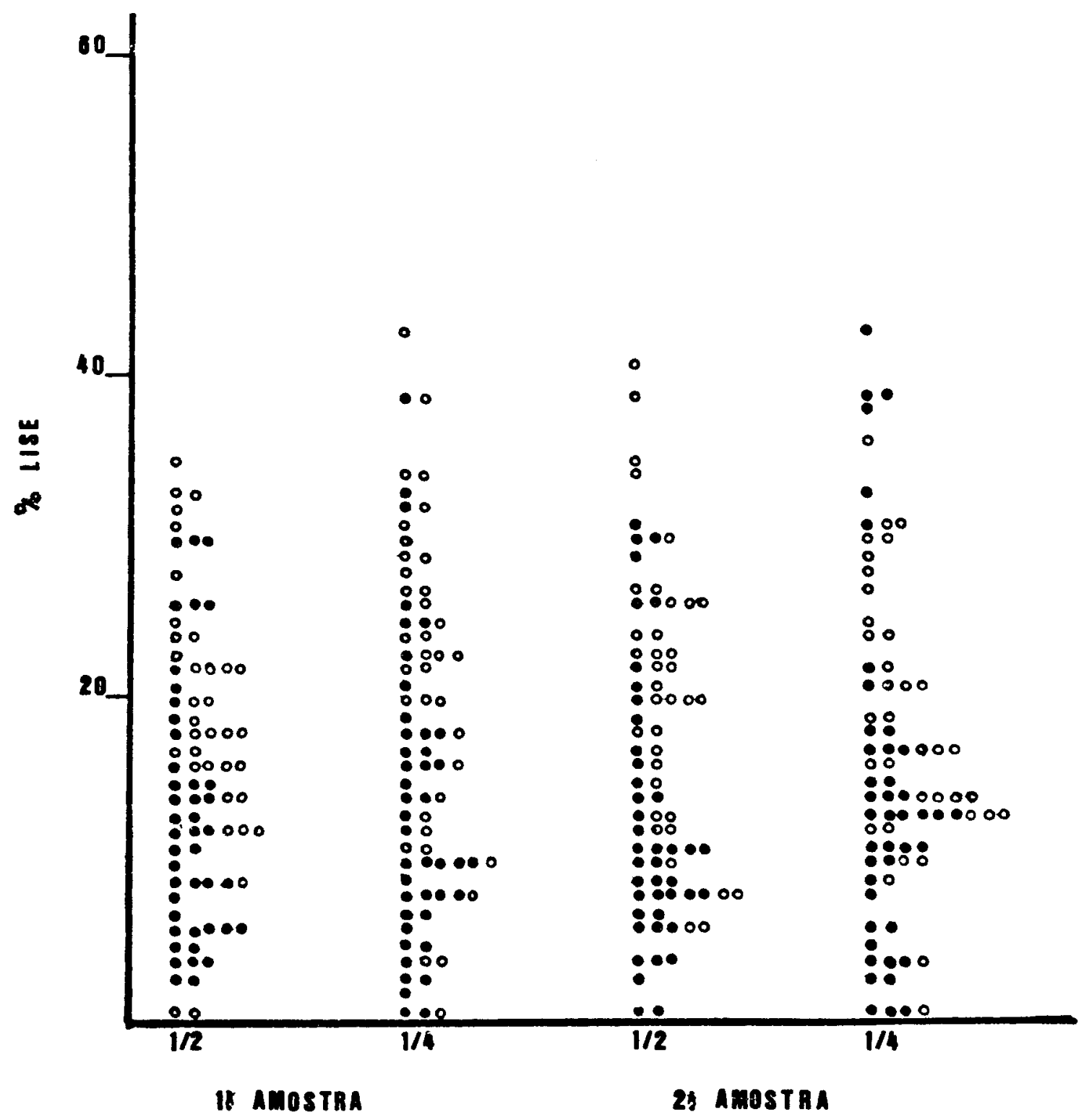

- manutençāo dos resultados em ambas amostras

O resultados variáveis

Fig. 4 -Grupo IV: distribuiçáo dos resultados de lise nas duas amostras (diluiçoes $1: 2$ e $1: 4$ ) de soro

\section{DISCUSSÃO}

A técnica de lise mediada por complemento é um método indireto e, como tal, sujeita a uma série de fatores que podem influenciar o resul tado. Esses fatores podem estar relacionados a animal experimental, ao parasita, à manipulação ou ao estado imunológico do paciente. Vi- 
LEVY, A. M. de A.; PEREIRA, V. L. \& BoAinain, E. - Avaliação da técnica de lise mediada por complemento em pacientes chagásicos crônicos tratados com drogas tripanosomicidas. Rev. Inst. Med. trop. São Paulo, 30 (1): $32-39,1988$

sando, por exemplo, verificar qual o erro relativo à contagem, submeteu-se um mesmo hemocitô metro a três técnicos que efetuavam as leituras, observou-se uma variação de $6 \%$. Todas essas dificuldades, pois, devem ser levadas em conta na avaliação dos resultados.

A tabela I expressa os resultados de lise me nor que $20 \%$ em todos os grupos. Aplicando-se o teste do "t"' Student verifica-se que nāo há diferença, estatisticamente significante no nível de $1 \%$, entre as diluiçôes 1:2 e 1:4. O mesmo pode ser observado na tabela II, na qual se mostra os resultados dos pacientes que apresentaram lise maior que $20 \%$. O uso de duas diluições, en tretanto, pode ser útil para um controle de qualidade. Sempre que os resultados nāo mostravam variaçāo dentro dos desvios padröes observados, optamos por repetiçāo da leitura ou mesmo da reação.

TABELA I

Distribuição dos soros com porcentagem de lise menor que $20 \%$

\begin{tabular}{|c|c|c|c|c|c|c|c|c|c|c|c|c|c|c|}
\hline & \multirow{2}{*}{\multicolumn{2}{|c|}{$\begin{array}{c}\text { Grupo I } \\
\text { IA }\end{array}$}} & \multicolumn{4}{|c|}{ Grupo II } & \multicolumn{4}{|c|}{ Grupo III } & \multicolumn{4}{|c|}{ Grupo IV } \\
\hline & & & \multicolumn{2}{|c|}{$1 A$} & \multicolumn{2}{|c|}{$2 A$} & \multicolumn{2}{|c|}{$1 \mathrm{~A}$} & \multicolumn{2}{|c|}{$2 \mathrm{~A}$} & \multicolumn{2}{|c|}{$1 A$} & \multicolumn{2}{|c|}{$2 \mathrm{~A}$} \\
\hline & $1: 2$ & $1: 4$ & 12 & 14 & 12 & $1: 4$ & $1: 2$ & $1: 4$ & 1.2 & $1: 4$ & $1: 2$ & $1: 4$ & $1: 2$ & $1: 4$ \\
\hline $\mathrm{n}$ & 20 & 20 & 3 & 3 & 3 & 3 & 36 & 36 & 36 & 36 & 12 & 12 & 12 & 12 \\
\hline $\bar{x} \pm D p\left(r_{r}\right)$ & $10 \pm 7$ & $9 \pm 7$ & $6 \pm 4$ & $5 \pm 3$ & $9 \pm 6$ & $8 \pm 6$ & $11 \pm 5$ & $10 \pm 6$ & $9 \pm 5$ & $9 \pm 5$ & $10 \pm 7$ & $12 \pm 7$ & $9 \pm 6$ & $11 \pm 5$ \\
\hline $\min \max (r)$ & $0-20$ & $0-19$ & $2-10$ & $3-8$ & $2-15$ & $1-20$ & $2-20$ & $2-20$ & $0-20$ & $0-20$ & $2-20$ & $2-20$ & $0-17$ & $4-20$ \\
\hline $\mathrm{Si}$ & $n s$ & ns & $n s$ & $\mathrm{~ns}$ & $\mathrm{~ns}$ & $\mathrm{~ns}$ & ns & ns & $\mathrm{ns}$ & ns & ns & ns & ns & $\mathrm{ns}$ \\
\hline
\end{tabular}

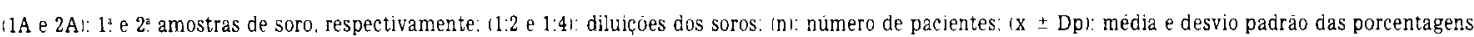
de lise: (min máxl: valores minimo e máximo das porcentagens de lise encontradas nos respectivos grupos: (Si): significancia entre as diluiçoes 1:2 e 1:4: (ns): nảo significante.

TABELA II

Distribuiçāo dos soros com porcentagem de lise maior que $20 \%$

\begin{tabular}{|c|c|c|c|c|c|c|c|c|c|c|c|c|}
\hline & \multicolumn{4}{|c|}{ Grupo II } & \multicolumn{4}{|c|}{ Grupo III } & \multicolumn{4}{|c|}{ Grupo IV } \\
\hline & \multicolumn{2}{|c|}{$1 \mathrm{~A}$} & \multicolumn{2}{|c|}{$2 \mathrm{~A}$} & \multicolumn{2}{|c|}{$1 \mathrm{~A}$} & \multicolumn{2}{|c|}{$2 \mathrm{~A}$} & \multicolumn{2}{|c|}{$1 \mathrm{~A}$} & \multicolumn{2}{|c|}{$2 \mathrm{~A}$} \\
\hline & $1: 2$ & $1: 4$ & $1: 2$ & $1: 4$ & $1: 2$ & $1: 4$ & $1: 2$ & $1: 4$ & $1: 2$ & $1: 4$ & $1: 2$ & $1: 4$ \\
\hline $\mathrm{n}$ & 12 & 12 & 12 & 12 & 7 & 7 & 7 & 7 & 4 & 4 & 4 & 4 \\
\hline$\vec{x} \pm D p(\%)$ & $38 \pm 19$ & $43 \pm 17$ & $32 \pm 17$ & $29 \pm 14$ & $26 \pm 3$ & $28 \pm 5$ & $27 \pm 4$ & $33 \pm 6$ & $37 \pm 20$ & $35 \pm 11$ & $38 \pm 17$ & $33 \pm 13$ \\
\hline $\min / \max (\%)$ & $21-55$ & $21-63$ & $22-75$ & $22-55$ & $21-29$ & $22-38$ & $21-30$ & $21-42$ & $22-57$ & $21-57$ & $21-50$ & $21-40$ \\
\hline $\mathrm{Si}$ & $\mathrm{ns}$ & ns & $\mathrm{ns}$ & $\mathrm{ns}$ & ns & $\mathrm{ns}$ & ns & ns & $\mathrm{ns}$ & ns & ns & $\mathrm{ns}$ \\
\hline
\end{tabular}

(1A e 2A): 1: e 2: amostras de soro. respectivamente; $11: 2$ e 1:4): diluiçoes dos soros; (n): numero de pacientes; $(x \pm$ Dp): média e desvio padrão das porcentagens de lise; (mím max): valores minimo e máximo das porcentagens de lise encontradas nos respectivos grupos: (Sii: significancia entre as diluiçōes $1: 2$ e 1:4: (ns): nāo significante.

Os resultados encontrados no Grupo I foram compativeis com os encontrados por outros au tores $^{11,}{ }^{12}$, atestando, assim a especificidade do método (100.0\%) de acordo com os conceitos de GALEN e GAMBINO?. Usando o cálculo preconizado por estes autores, a sensibilidade foi de $83,3 \%$, considerando as duas amostras, adotando-se como valor discriminante $20 \%$ de lise dos tripomastigotas. A eficiência ${ }^{13}$ de reação, isto é, a sua capacidade de diagnosticar tanto positivos quanto negativos, em duas amostras foi de 0,921.

Nos pacientes do Grupo II, houve concordância nos resultados de $\mathbf{8 3 , 4 \%}$ nas duas amostras. Nos pacientes do Grupo III essa concordância foi de $54,4 \%$ ao passo que no Grupo IV foi de $80.0 \%$. 
LEVY, A. M. de A.; PEREIRA, V. L. \& BOAINAIN, E. - Avaliaçāo da tecnica de lise mediada por complemento em pacientes chagásicos crónicos tratados com drogas tripanosomicidas. Rev. Inst. Med. trop. São Paulo, 30 (1): 32 -39, 1988

Assumindo-se como valor discriminante o indice de $20 \%$ de lise, os resultados mostram que, teoricamente, o tratamento teria sido eficaz em cerca de $50 \%$ dos casos, independente do tempo decorrido após a administraçào da droga (menos ou mais de seis anos). Ressalte-se que não se cogita da avaliaçāo na evolução dos resultados de lise, desde que nāo se dispōe do valor da mesma antes do tratamento.

Taxas de lise entre 21 e $42 \%$ foram apresen tadas por sete soros do Grupo III e quatro soros do Grupo IV. Estes pacientes apresentaram pro vas parasitológicas negativas tanto quanto aqueles que apresentaram lise menor que $20 \%$. É difícil supor que tais pacientes não estejam ainda "curados", pois os pacientes do Grupo III foram tratados há mais de seis anos. Quanto ao paciente do Grupo IV que apresentou valores bastante elevados (Fig. 4), pensamos que tais valores poderiam corresponder ou a um resultado falso positivo, ou indicar persistência da infec çāo com possibilidade de um futuro xenodiagnóstico positivo.

Nas figuras 3 e 4 verifica-se que 36 soros (45.6\%) do Grupo III e 4 soros $(20.0 \%$ ) do Grupo IV apresentaram resultados que variaram de 0 a $50 \%$ podemos ser classificados, ora como positi vos, ora como negativos, dependendo da amos tra. Diante das provas parasitológicas persistentemente negativas, preferimos classificá-los como inconclusivos. O seguimento laboratorial desses pacientes (o que está sendo realizado) poderá esclarecer o significado dos valores encon trados na lise mediada por complemento, em função das provas parasitológicas.

\section{SUMMARY}

Evaluation of complement mediated lysis in chronic chagasic patients treated with trypanosomicidal drugs.

Levels of lytic antibodies were determined by complement mediated lysis (CoML) in chronic chagasic patients treated with nifurtimox orbenznidazole. Two groups of patients were stu died: one who had been treated more than six years ago and another with less than six years since treatment, although serologic reactions re- mained positive. CoML was carried out in two samples obtained from patients on different occasions, in test groups as well as in positive controls. In view of results observed sensitivity of reaction $(83.3 \%)$ and its specifity $(100.0 \%)$ were calculated. It was observed that about half of the patients presented lysis up to $20 \%$ and this result may corroborate "parasitological cure". It was noted that $43.6 \%$ of patients treated more than six years ago and $20.0 \%$ of patients with less than six years since treatment presented variable results, either positive or negative, differing for each sample from the same individual. Such results were thus considered as inconclusive, since parasitological tests remain negative. A prolonged follow-up may shed light over such results.

\section{AGRADECIMENTOS}

A Profa. Dra. Judith K. Kloetzel - Instituto de Medicina Tropical de São Paulo - Universidade de São Paulo - pela revisão do texto em inglês.

Ao Dr. Ricardo Manrique - Instituto "Dante Pazzanese" de Cardiologia - pela leitura crítica do texto.

\section{REFERẼNCIAS BIBLIOGRÁFICAS}

1. BARACCHINI, O. \& SILVA, M. B. - Emprego da técnica de Kolmer, modifieada na fixação de complemento, usando antígeno metrlico de Trypanosoma cruxi no diagnóstico da doença de Chagas. Rev. Inst. A. Lutz (S. Paulo), 29-30: $73-79,1969 / 70$.

2. BOAINAIN, E. - Tratamento etiológico da doença de Chagas na fase crônica. Rev. goiana Med., 25: 1-60, 1979.

3. BRENER, Z.; RAMIREZ, L. E.; KRETTLI, A. U. \& CAN CADO, J. R. - EVI antibodies in patients with Chagas disease: relationship with anti-Trypanosoma cruzi imunoglobulins and effects on specific treatment. Mem. Inst. Osw. Cruz, 78: 437-442, 1983

4. CAMARgo, M. E. - Fluorescent antibody test for the serodiagnosis of American trypanosomiasis: Technical modification employing preserved culture forms of Trypanosoma cruzi in a slide test. Rev. Inst. Med. trop. S. Paulo, 8: $227-234,1966$.

5. CHIARI, E.; DIAS, J. C. P.; LANA, M. \& CHIARI, C. A. - Hemocultures for the parasitological diagnosis of human Chagas'disease in chronic phase. In: CONGRESSO INTERNACIONAL SOBRE DOENCA DE CHAGAS. Anais. Rio de Janeiro, 1979. p. N1-N5. 
LEVY, A. M. de A.; PEReira, V. L. \& BOAINAIN, E. - Avaliação da técnica de lise mediada por complemento em pacientes chagásicos crónicos tratados com drogas tripanosomicidas.

Rev. Inst. Med. trop. Sâo Paulo, 30 (1): 32-39, 1988.

6. FUCHS, A. P.; FIORATTI, V. L.; MELLO, V. A. \& BOAINAIN, E. - Diagnóstico sorológico na doença de Chagas. Estudo comparativo de diferentes técnicas. Rev. Inst. Med. trop. S. Paulo, 22: 242-245, 1980.

7. GALEN, R. S. \& GAMBINO, S. R apud. GUIMARĀES M. C. S. - Exames de laboratório, sensibilidade, especificidade, valor preditivo. Rev. Soc. bras. Med. trop., 18: $117-120,1985$.

8. GALVĀO, L. M. C.; CANÇADO, J. R.; BRENER, Z. \& KRETTLI, A. U. - Controle de cura a través da lise mediada por complemento (LMCo) e hemocultura em pacientes chagásicos submetidos a tratamento específico. In: REUNIĀO ANUAL SOBRE PESQUISA BÁSICA EM DOENÇA DE CHAGAS, 12., Caxambú, 1985. Programa e resumos. p. 139.

9. KRETTLI, A. U. \& BRENER, Z. - Protective effects of specific antibodies in Trypanosoma cruzi infections. $J$. Immunol., 116: 755-760, 1976

10. KRETTLI, A. U. - Efeito de anticorpos e do complemento sobre tripomastigotas sangüíneos de camundongos infectados com Trypanosoma cruzi Belo Horizonte, 1978. (Tese de doutoramento - Universidade Federal de Minas Gerais).

11. KRETTLI, A. U. - Protective antibodies in Trypanosoma cruzi infections: detection, functional activity and possible mechanisms of trypomastigote killing "in vivo" and “in vitro". Mem Inst. Osw. Cruz, 79 (supl.): 59-65, 1984
12. KRETTLI, A. U.; CANÇADO, J.R. \& BRENER, Z - Criterion of cure of human Chagas' disease after specific chemo terapy: recent advances. Mem. Inst. Osw. Cruz, 79 (supl.): $157-164,1984$.

13. PRIMAVERA, K. S. C. - Eficiencia dos antígenos das formas evolutivas do Trypanosoma cruzi para a deteç̧ão de anticorpos das classes A, M, E, G, nas diferentes formas clínicas da infecçào chagásica, pela reação de imunofluorescéncia indireta. Sāo Paulo, 1985. (Tese de doutoramento - Instituto de Ciências Biomédicas da Universidade de São Paulo).

14. ROMEIRO, S. A.; TAKEHARA, H. A. \& MOTA, I. - Isoty pe of lytic antibodies in serum of Chagas'disease patients. Clin. exp. Immunol., 55: 413-418, 1984

15. SILVA, L. H. P. \& NUSSENZWEIG, V. - Sobre uma cepa de Trypanosoma cruzi altamente virulenta para o camundongo branco. Folia clín. biol. (S. Paulo), 20: 191-208, 1953.

16. STONI, P. D.; BOLSI, F. L. \& YANOVSKY, J. F. - Reacción de aglutinación directa para diagnóstico de la enfermedad de Chagas. Utilizacion sistematica del 2-mercaptoetanol para la eliminacion de las aglutininas inespe cificas. Medicina (B. Aires), 31: 67-72, 1975.

17. UMEZAWA, E. S. - Comunicaçảo pessoal. (1985).

Recebido para publicaçāo em 24/4/1987. 